\title{
Methodology for Evaluation of District Heating Network Efficiency
}

\author{
Daniel Anthony Howard ${ }^{1}$, Konstantin Filonenko ${ }^{1}$, Frederik Stjernholm Busk ${ }^{2}$, and Christian Veje ${ }^{1}$ \\ ${ }^{1}$ University of Southern Denmark, The Maersk Mc-Kinney Moller Institute, Campusvej 55, 5230 Odense M, Denmark \\ ${ }^{2}$ EWII, TREFOR Varme, Kokbjerg 30, 6000 Kolding, Denmark
}

\begin{abstract}
The definition of overall district heating network performance indicators is under-investigated in the literature. This study reviews existing methods of performance estimation and develops a convenient methodology for an array of district heating networks applied to a Danish case study. Performances of the networks with state-of-art pipe transmission coefficients are compared to older traditional pipes using an effective average approach. The reported efficiencies and analysis of contributing factors show, that a single parameter is not sufficient to compare large-scale district heating systems and a multiparametric analysis must be employed. The effective average total heat transmission coefficient is evaluated based on the Technical Evaluation Factor and a multivariate regression is performed on typical sets of network parameters: pipe type, pipe series, pipe age, and operational temperature. The developed methodology is applied to testing an array of geographically independent district heating networks, pointing to possible performance bottlenecks, and discussing potential remedies.
\end{abstract}

\section{Introduction}

District heating (DH) is a technology allowing the distribution of a heated fluid provided by one or more central heat production units through insulated pipes. A DH network may be connected to a single heating unit, which is often the case for smaller networks. However, larger networks normally have multiple heating units, which are utilized based on the merit order dispatch. In Denmark, DH is a well-established technology that was implemented in the early 20th century, which has now grown to cover approximately $64 \%$ of the domestic heat demand $[1,2]$.

As this technology matured over the decades, heat production from multiple sources and consumption of different types have gradually evolved $[2,3]$ and partially integrated with other energy sectors [4, 5] and IoT networks $[6,7]$. A need to optimize the new energy grid infrastructure attracted a large amount of academics into the field, particularly focusing on process control optimization under transition to $100 \%$ renewable economy [8].

On the other hand, focusing very much on increasing the overall system efficiency through control of plant processes, energy delivery, and storage in lowtemperature networks, the improvement of conventional distribution design, its benchmarking and testing is less frequently addressed [9].

The new infrastructure relying on such local effects, as energy-efficiency in buildings, degree of process automation and supply/return/consumer temperature regimes, requires improved distribution technologies, and, as a result, more elaborate methods and performance indicators are required to estimate distribution network efficiency relying on various parameters [10].

In this study, we take one step further to understand how the Danish distribution network efficiency can be estimated from a multivariate statistics point of view. To make our conclusions more transparent, we focus on a moderate number of parameters, mostly related to the pipe heat loss. This set of parameters should serve as a basis for further research on the topic since pipe losses are a decisive financial factor motivating transition to low-temperature district heating.

Conventionally, the Danish DH grid is divided into multiple heating networks which are operated independently. Currently, the efficiency of a network is calculated as the amount of heat sold divided by the amount of heat produced $[11,12]$ :

$$
\eta=\frac{Q_{s}}{Q_{p}}
$$

This approach gives an overall indication of the performance but complicates the comparison of separate DH networks as these may have significantly different characteristics. Characteristics may include the number of consumers, age of the pipes, weather conditions, etc. Therefore, to efficiently optimize and compare $\mathrm{DH}$ networks, the influence of relevant parameters should be determined as these may also vary between DH networks [13]. 


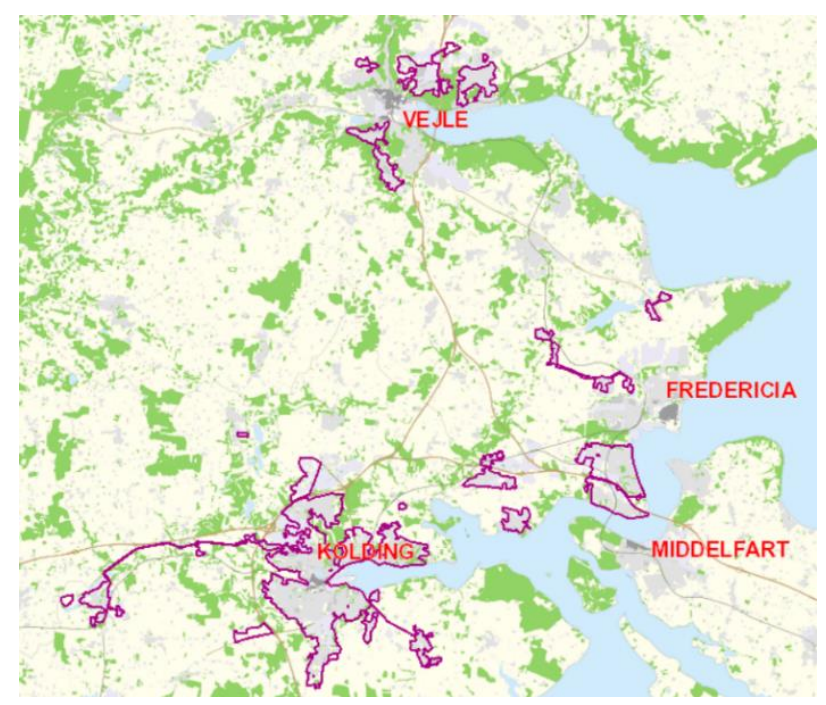

Fig. 1. The geographical layout of the DH areas administered by the utility company.

Trefor Varme is a DH distribution company supplying district heat to consumers located in Vejle, Kolding, and Fredericia (see Figure 1). Trefor Varme operates multiple DH networks in this region, fourteen of which are relevant to this study. The first objective, therefore, is to allow Trefor Varme to compare their networks internally and externally. The second objective is to get an insight into the most influential parameters in each network thereby establishing a tool for identifying the most cost-beneficial areas those with the highest improvement potential.

\section{Methodology}

\subsection{Pipe parameters}

Fundamentally, heat flow can be described as:

$$
\Phi=\rho c_{p} q_{v}\left(T_{s}-T_{r}\right)
$$

Where $\Phi$ is the heat flow, $T_{s}$ is the supply temperature, $T_{r}$ is the return temperature, $q_{v}$ is the volume flow rate, $c_{p}$ is the specific heat at constant pressure, and $\rho$ is the density of the fluid. As explained in [14], the total thermal resistance in an insulated pipe can be described as:

$$
R=\frac{1}{h_{1} A_{1}}+\sum_{i=1}^{3} \frac{\ln \left(r_{i+1} / r_{i}\right)}{2 \pi L k_{i}}+\frac{1}{h_{2} A_{2}}
$$

As stated in $[12,13]$ the total heat loss within a DH system can be calculated as:

$$
Q_{l}=Q_{p}-Q_{s}=K \cdot 2 \pi d_{a} L \cdot G
$$

where $\mathrm{K}$ is the effective average of the total heat transmission coefficient, $d_{a}$ is the average pipe diameter to pipe length, $\mathrm{L}$ is the route length, and $\mathrm{G}$ is the degree time number expressed as stated in [18]:

$$
G=\frac{T_{s}+T_{r}}{2}+8760 T_{g}
$$

Per [13], the annual heat loss primarily depends on four parameters which are: total heat transmission coefficient $K$, average pipe diameter $d_{a}$, distribution temperature level $\mathrm{G}$, and linear heat density $\mathrm{Q}_{\text {sold }} / \mathrm{L}$. The overall heat transfer coefficient can, therefore, be calculated as [15].

$$
K=Q_{p} / 2 \pi d_{a} L G
$$

For the sake of comparison, the annual heat loss is often expressed relative to the heat input to compare systems based on the relative distribution heat loss

$$
q_{l}=\frac{Q_{l}}{Q_{p}}=1-\eta
$$

\subsection{Effective averages}

Data from the Danish utility company was sorted and validated, see Table 1 and 2 for an overview. The hourly production is calculated using Equation (2) and the efficiency is calculated via Equation (1) for 2015 and 2017 , for which the data is available for all considered networks.

Table 1. Data sets and their availability in the project

\begin{tabular}{|c|c|}
\hline Data type & Availability \\
\hline Production data & $2009-2017$ \\
\hline Sales data & $2014-2019$ \\
\hline Pipe records & $1970-2019$ \\
\hline Pipe data & N/A \\
\hline Degree-Day record [16] & $2009-2017$ \\
\hline
\end{tabular}

Table 2. DH network parameters

\begin{tabular}{|c|c|c|c|c|c|}
\hline No & Area & N & L, km & $\begin{array}{c}\text { AHP, } \\
\text { MWh }\end{array}$ & $\begin{array}{c}\text { AHS, } \\
\text { MWh }\end{array}$ \\
\hline 1 & Bredballe & 2256 & 53.84 & 33341 & 26393 \\
\hline 2 & Egeskov & 606 & 15.25 & 7894 & 5488 \\
\hline 3 & Snoghøj & 1665 & 44.44 & 28527 & 22808 \\
\hline 4 & Erritsø & 4097 & 98.41 & 65912 & 50958 \\
\hline 5 & Hover & 85 & 4.06 & 3474 & 3184 \\
\hline 6 & Hvidsminde & 1899 & 47.10 & 38468 & 27419 \\
\hline 7 & Kolding Nord & 8309 & 222.00 & 232661 & 158963 \\
\hline 8 & Kolding M/S & 15691 & 338.81 & 329874 & 254474 \\
\hline 9 & Nørremarken & 2248 & 60.88 & 54672 & 44637 \\
\hline 10 & Skærbæk & 1292 & 30.09 & 16116 & 11362 \\
\hline 11 & Strandhuse & 3588 & 80.62 & 49332 & 36373 \\
\hline 12 & Gludsminde & 2591 & 54.17 & 49541 & 43355 \\
\hline 13 & Taulov & 1655 & 43.28 & 24788 & 18260 \\
\hline 14 & Ullerup & 962 & 31.90 & 18907 & 13192 \\
\hline
\end{tabular}


The paper examines a series of DH networks that are comprised of varying pipe sections documented in the company pipe records, see Table 1 . As the pipes are of varying length, the pipe parameters must be adjusted according to the influence of the pipe in the entire network. The following approach was utilized: the pipe parameters can be adjusted to the relative length of a pipe, $\mathrm{L}_{\text {pipe }}$, compared to the total length of an individual $\mathrm{DH}$

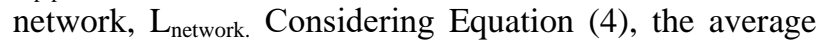
pipe diameter $d_{a}$ in the network is found as:

$$
d_{a}=\sum_{i=1}^{n} f_{a, i} d_{\text {pipe }, i}
$$

where

$$
f_{a, i}=\frac{L_{\text {pipe }, a}}{L_{\text {network }, i}}
$$

Is the length of the pipe section divided by the total length of pipes within the given network and characterizes the relative influence of each pipe in the pipe network based on length.

The approach proposed by Equation (8) can be adjusted to find the effective average influence on an array of parameters, e.g. pipe series and age, by substituting $\mathrm{d}_{\text {pipe,i }}$ with the desired parameter. This overall approach was performed for a selection of relevant parameters, which were then correlated with the DH network efficiency. The examined parameters include operation temperature, pipe series, pipe age, number of twin pipes, energy density, pipe lambda.

For each parameter, a regression was performed to assess the significance of the individual parameters for comparison between the DH networks. Using the attained knowledge regarding the parameter influence a multiparameter regression was performed showing the combined parameter trend towards efficiency. After examining the overall correlation between individual DH parameters and the efficiency, the average effective heat transfer coefficient of each $\mathrm{DH}$ area was determined using (4). The heat transfer coefficient for pipes of varying quality and inner diameter were calculated according to EN 13941 [17]. Series 1 and 3 Conti traditional steel pipes were used as the low- and highquality boundaries, respectively and mineral wool pipes were used as a reference [18].

Finally, by comparing the individual DH networks based on specific network characteristics, an estimate of the network's overall performance was determined by a technical evaluation factor $[18,15]$.

$$
T E F=\frac{K_{\text {network }}-K_{\text {high }}\left(d_{a}\right)}{K_{\text {low }}\left(d_{a}\right)-K_{\text {high }}\left(d_{a}\right)}
$$

Where $K_{\text {network }}$ is calculated according to Equation (6) and $\mathrm{K}_{\text {high }}$ and $\mathrm{K}_{\text {low }}$ are determined through regression of the results obtained following EN 13941 [17].

\section{Results}

Based on the methodology the results presented in this section were obtained. Initially, the efficiencies for 2015 and 2017 were calculated using Equation (1) and compared to check for consistency within the data sets. Good consistency between the efficiencies in 2015 and 2017 was evident. Based on this, it is reasoned that there are no significant parametric changes in the range between 2015 and 2017. Therefore, the 2015 and 2017 data are used for analysis and investigation.

The calculated efficiencies in each area for 2015 and 2017 are shown in Figures 2 and 3, respectively, for each of the 14 networks characterized by different production capacities and sales

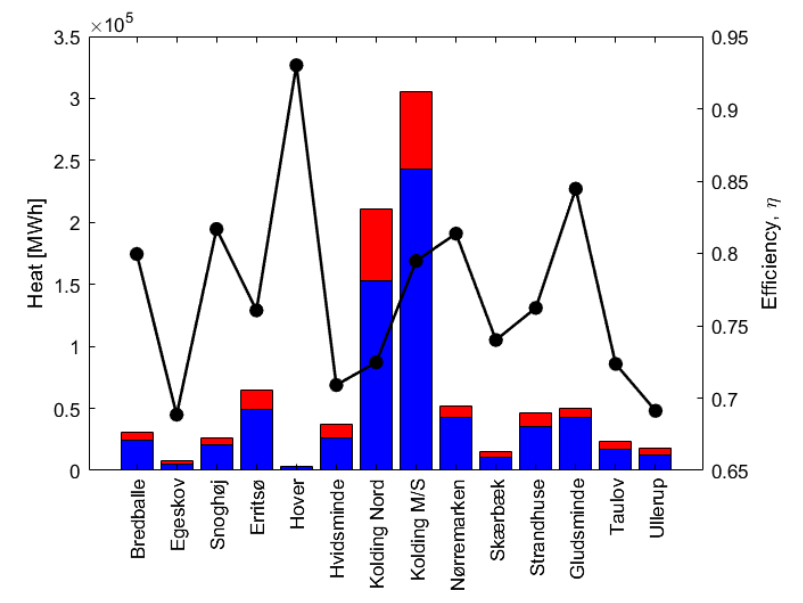

Fig. 2. Production and sales for all DH networks (2015)

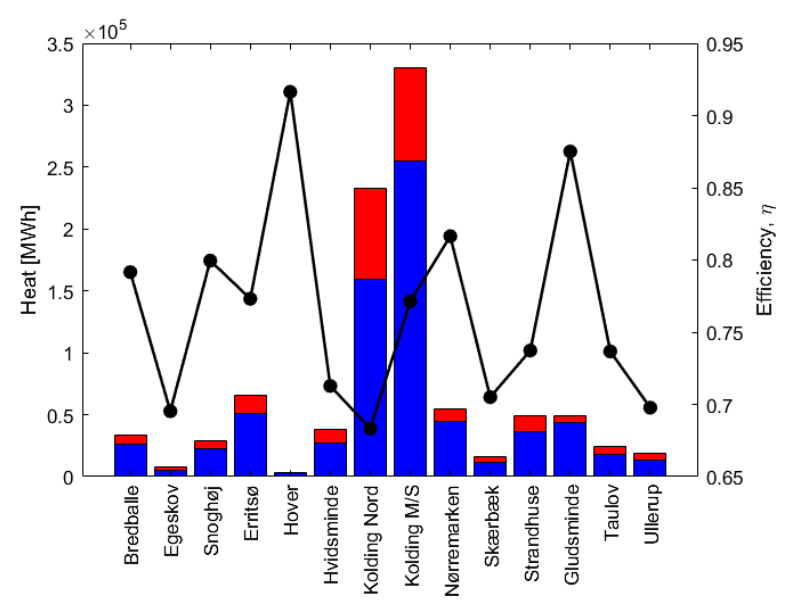

Fig. 3. Production and sales for all DH networks (2017)

The observed significant production difference between the $\mathrm{DH}$ networks can be partially attributed to the population and industry density present in the given area. Additionally, the production must compensate for any losses present in the grid and is hence dependent on the pipe layout of the DH network. Figures 2 and 3 expose a good correlation between and the difference in production and sales and the standard efficiency measure defined by Equation (1).

\subsection{Parametric analysis with a single variable}

As stated in Section 3, a set of parameters correlation towards efficiency was examined. In the following section, the findings will be presented together with the respective coefficients of determination. Furthermore, a 
$95 \%$ prediction interval is outlined. The term 'corrected' is used when the parameters have been adjusted according to Equation (8). Initially, the regression was done for pipe series, which refers to the insulation class of the pipe and the penetration of twin pipes in every $\mathrm{DH}$ network.

Figure 4 shows a weak correlation $\left(\mathrm{R}^{2}=0.36825\right)$ between the pipe series and the efficiency value used for comparison. The weak correlation can, to some extent, be attributed to the omission of pipe diameter. Even though a higher average series value indicates better insulation of the pipes, the heat loss is highly dependent on the diameter, see Equations (3) and (4), i.e. a DH network with a high overall series and large pipes might have lower efficiency compared to a network with a lower overall series values and smaller pipes.

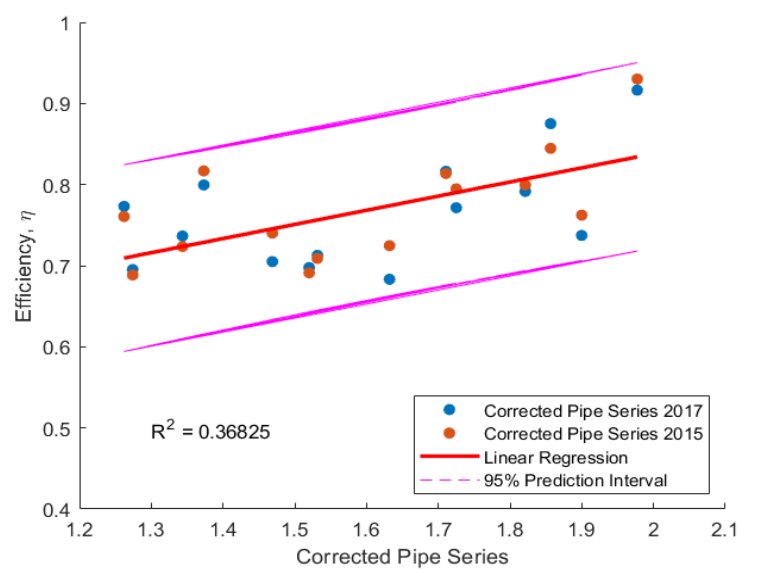

Fig. 4. Pipe series in DH networks vs. efficiency.

Figure 5 shows a moderate correlation $\left(\mathrm{R}^{2}=0.64948\right)$ between the penetration of twin pipes and efficiency indicating that the efficiency also rises, as a higher percentage of the pipes become twin-pipes (the heat loss associated with a twin-pipe can be found following [12]). An essential consideration for twin pipes is that they are limited to a DN250 [19], which may result in that areas with a requirement for larger pipes that will be negatively affected.

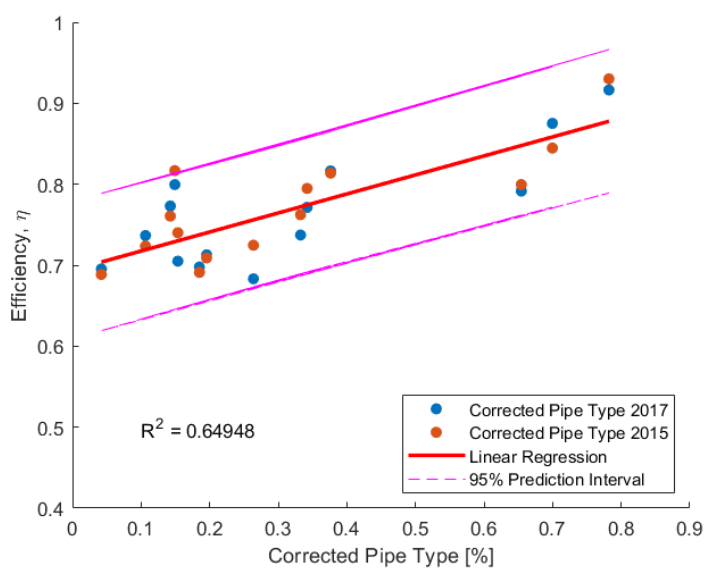

Fig. 5. Twin pipes in DH networks vs. Efficiency

Figure 6 shows a moderate correlation $\left(R^{2}=0.54078\right)$ between the pipe age and efficiency. As the quality of
DH network pipes becomes increasingly developed, the overall quality of pipes rises, older pipes may, therefore, be of lower quality and more prone to faults. Pipes in the Conti series are produced with a barrier preventing the leakage of gasses. This means that the Conti pipes in theory experience no operational decay over time.

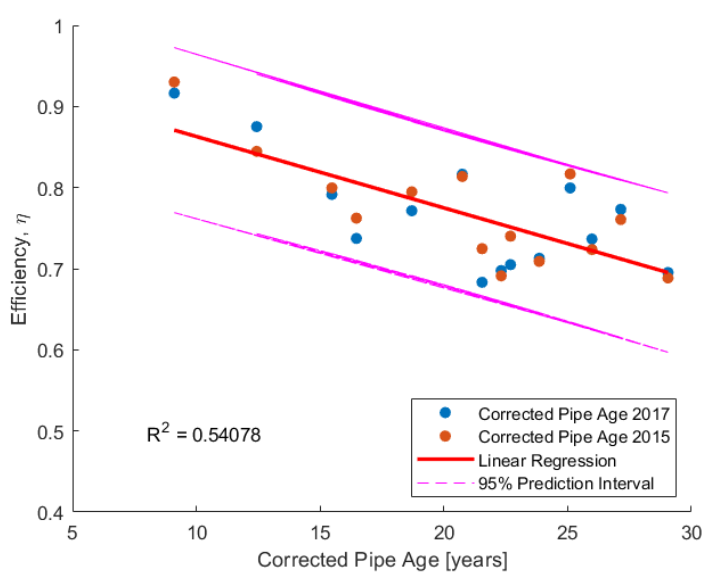

Fig. 6. Pipe age in DH networks vs. efficiency.

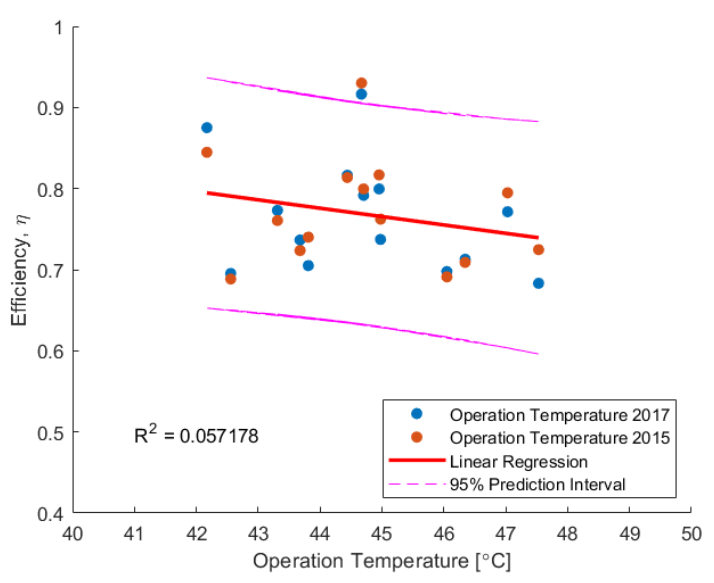

Fig. 7. Operating temperature vs. efficiency.

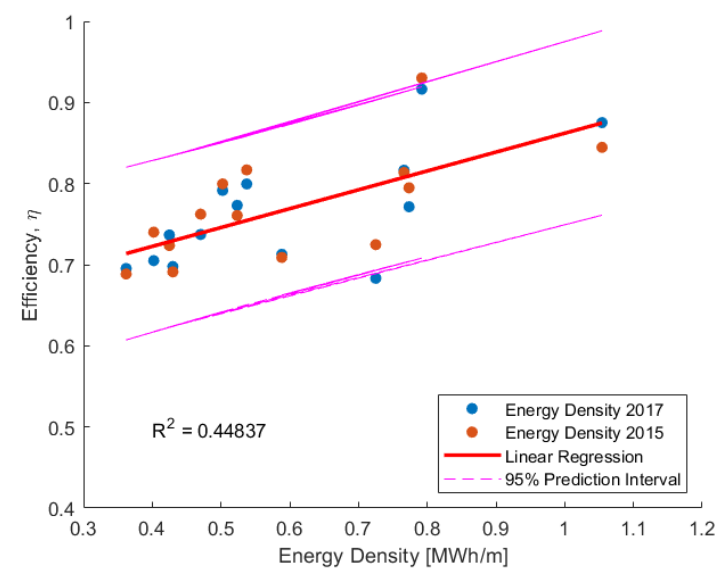

Fig. 8. DH network energy density vs. efficiency.

Figure 7 shows a very poor correlation $\left(\mathrm{R}^{2}=\right.$ 0.057178) between the operating temperature and efficiency. Note that the efficiency is highly dependent on the operation temperature, see Equations (2) and (4). 
However, regression shows that for comparison of $\mathrm{DH}$ networks the temperature does not play a significant role, i.e. high operation temperature does not necessarily imply low efficiency. This can properly be attributed to the operating temperature being a secondary parameter derived from the network topology.

Figure 8 shows a moderate correlation $\left(R^{2}=0.44837\right)$ between energy density and efficiency. The energy density, to some extent, expresses the spread of consumers within a DH network. An increasing spread of consumers results in the water needing to cover a larger distance hence resulting in an increased heat loss. The energy density is prone to error when considering consumer characteristics and distribution, e.g. new lowenergy housing results in a low energy density.

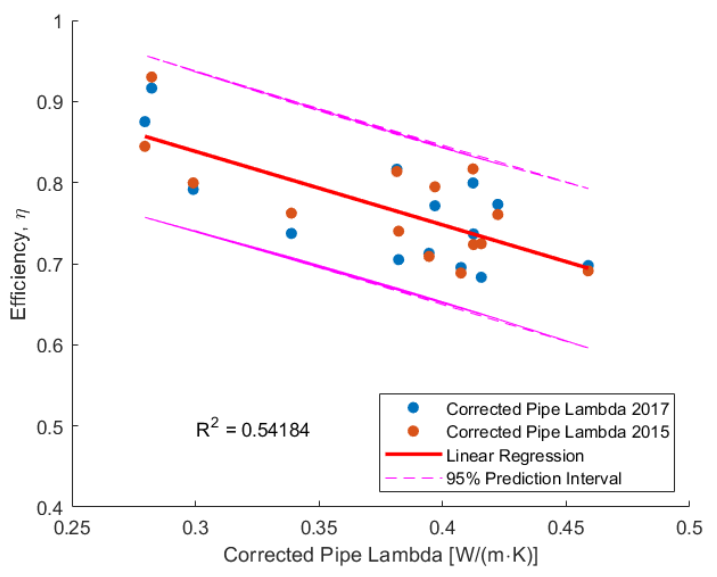

Fig. 9. Average pipe lambda vs. efficiency.

Looking at the correlation towards the corrected lambda values observed in Figure 9, there is a coefficient of determination of $\mathrm{R}^{2}=0.54184$. The lambda value covers the parameters shown in Figures 4-8 and is hence subject to the same conditions. For further consideration, the lambda value is excluded because it is considered beneficial to evaluate the individual parameters instead of collecting them into a single parameter.

\subsection{Multiparametric analysis}

Generally, none of the regression models yielded any convincing coefficients of determination, which are all significantly below 0.9 . However, the coefficient of determination may express that the parameters only accounts for some of the correlations and that none of the individual parameters can compare to the efficiency all by itself. It can, therefore, be relevant based on the previously presented figures to determine a correlation between the most influential parameters, which can be joined into a multiparameter, presenting the overall correlation towards efficiency. The multiparameter is constructed based on an intuitive understanding of how each parameter depends on the overall efficiency provided by the single-parameter analysis. As an illustration, based on visual inspection of Figure 6, we assume that the age and efficiency are inversely proportional to each other, $\eta \sim 1 /$ age. By similar reasoning, the linear heat density is assumed to be directly proportional to the efficiency, $\eta \sim$ heat density. Generally, the proportionality is determined based on the slope of the regression line: if the slope is positive (negative), the direct (inverse) proportionality is assumed. Following this approach, the multiparameter can be constructed as:

$$
\eta \sim \frac{\text { series } \cdot \text { type } \cdot \text { heat density }}{\text { age }}
$$

The regression fit based on Equation (10) can be seen in Figure 10. Due to a small coefficient of determination for the pipe series regression $\left(R^{2}=0.36825\right)$, the series parameter can be omitted from the definition:

$$
\eta \sim \frac{\text { series } \cdot \text { heat density }}{\text { age }}
$$

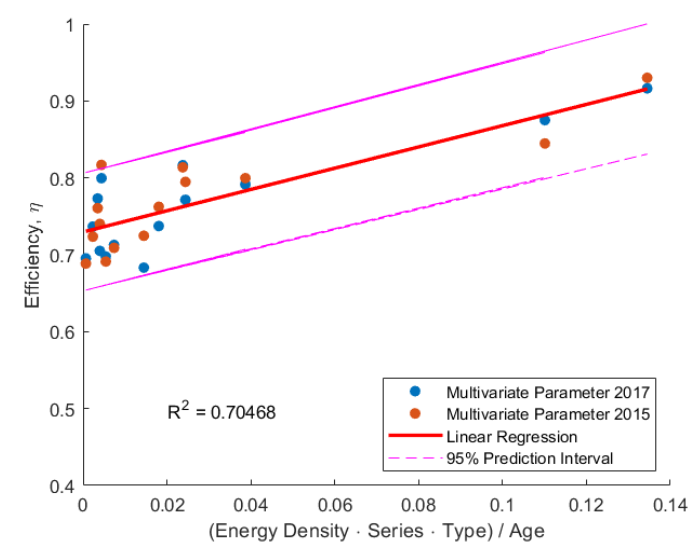

Fig. 10. Multiparameter regression.

The multiparameter regression corresponding to Equation (11) is plotted in Figure 11 and differs very little from that in Figure 10.

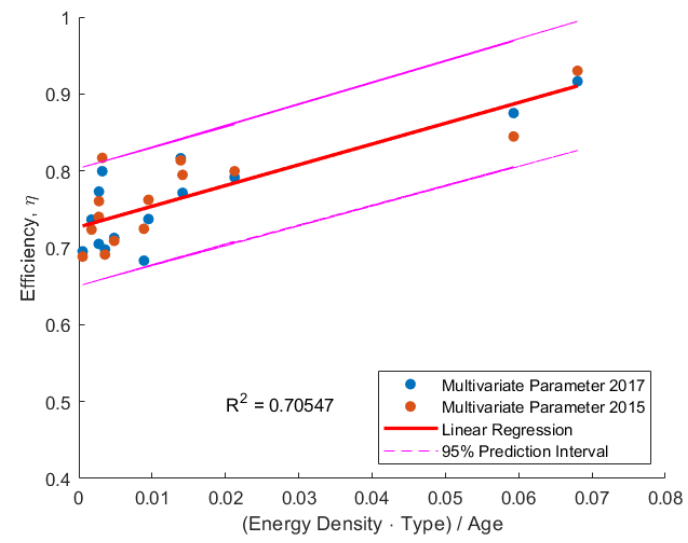

Fig. 11. Multiparameter regression excluding pipe series.

The highest value of the overall coefficient of determination $\mathrm{R}^{2}$ is around 0.7 , which still implies a poor correlation, but indicates that to compare different $\mathrm{DH}$ networks, several parameters should be considered, and the comparison cannot be made using a single parameter. The coefficient of determination could also suggest that parameters that have not been examined here are contributing to the correlation. 


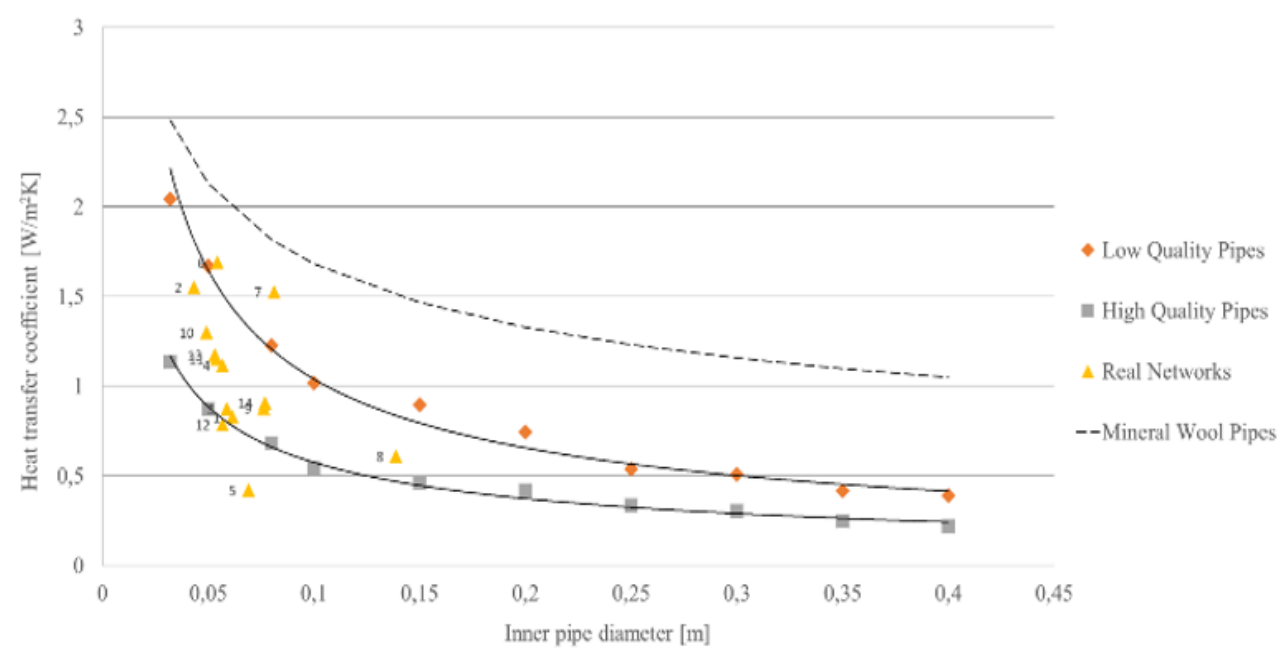

Fig. 12. Overall heat transfer coefficient for high quality, low quality and mineral wool pipes including area specific calculations.

\subsection{Technical evaluation factor}

As explained in Section 3, the TEF for each DH network was calculated from the effective average heat transfer coefficient found for different pipe diameters according to the known method [17]. The actual effective average heat transfer coefficients for the $\mathrm{DH}$ networks are calculated in Figure 12 as functions of inner pipe diameter based on DH network data for 2017.

The mineral wool pipes are described by the following function [18]:

$$
K_{\text {mineral wool }}\left(d_{a}\right)=0.7676 \cdot d_{a}^{-0.341}
$$

While the following functions describe the regression of the low- and high-quality pipes:

$$
\begin{aligned}
& K_{\text {low }}\left(d_{a}\right)=0.2251 d_{a}^{-0.664}\left(R^{2}=0.9827\right) \\
& K_{\text {high }}\left(d_{a}\right)=0.1364 d_{a}^{-0.625}\left(R^{2}=0.9865\right)
\end{aligned}
$$

Based on these, the TEF value for each network is calculated by using Equation (12) and summarized in Table 3. As can be concluded from Table 3, the DH network Kolding Nord is the area with the highest potential for renovation, and Hover is the network with the best performance. The reason that the TEF for Hover is negative is the high-quality pipes being evaluated as single series 3 steel Conti. Hover has a high penetration of twin pipes, and therefore, the effective average heat transfer coefficient is lower compared to the EN 13941 evaluation. To get a better understanding of how TEF relates to efficiency and heat loss, the methods are compared in section 3.4 .

Table 3. TEF Comparison of DH networks

\begin{tabular}{|c|c|c|c|c|c|c|}
\hline No & Area & $\begin{array}{c}\boldsymbol{d}_{\boldsymbol{a v}}, \\
\mathbf{m}\end{array}$ & $\begin{array}{c}\mathbf{G H}, \\
\mathbf{k W h}\end{array}$ & $\begin{array}{c}\boldsymbol{Q}_{\boldsymbol{d}}, \\
\frac{\boldsymbol{M W h}}{\boldsymbol{m}}\end{array}$ & $q_{l}$ & TEF \\
\hline 1 & Bredb. & 0.061 & 391598 & 20.8 & 0.50 & 7 \\
\hline 2 & Egeskov & 0.043 & 372789 & 30.5 & 0.36 & 69 \\
\hline
\end{tabular}

\begin{tabular}{|c|c|c|c|c|c|c|}
\hline 3 & Snoghøj & 0.059 & 393791 & 20.0 & 0.54 & 11 \\
\hline 4 & Erritsø & 0.057 & 379404 & 22.7 & 0.52 & 43 \\
\hline 5 & Hover & 0.069 & 391295 & 8.4 & 0.79 & -50 \\
\hline 6 & Hvidsm. & 0.054 & 405968 & 28.7 & 0.59 & 119 \\
\hline 7 & $\begin{array}{c}\text { Kolding } \\
\text { Nord }\end{array}$ & 0.081 & 416363 & 31.7 & 0.73 & 162 \\
\hline 8 & $\begin{array}{c}\text { Kolding } \\
\text { M/S }\end{array}$ & 0.139 & 411980 & 22.9 & 0.77 & 38 \\
\hline 9 & Nørrem. & 0.076 & 389288 & 18.4 & 0.77 & 35 \\
\hline 10 & Skærb. & 0.049 & 383770 & 29.5 & 0.40 & 52 \\
\hline 11 & Strand. & 0.054 & 394000 & 26.3 & 0.47 & 43 \\
\hline 12 & Gludsm. & 0.057 & 369418 & 12.5 & 1.05 & -5 \\
\hline 13 & Taulov & 0.053 & 382603 & 26.3 & 0.42 & 44 \\
\hline 14 & Ullerup & 0.077 & 403382 & 30.2 & 0.43 & 41 \\
\hline
\end{tabular}

\subsection{Ranking}

The described methodology is applied to compare the DH networks by comparing their (1) efficiency, (2) RHL, and (3) TEF. Based on these methods, the networks are ranked from best to worst in the last column of Table 4 .

Table 4 shows that using the efficiency defined by Equation (1) and RHL defined by Equation (7) for comparison of the DH networks yields the same ranking. However, by using TEF, the ranking of the DH networks is slightly altered. The change in ranking is shown in Table 4 by $\Delta$, indicating how the rank of the DH network changes depending on the efficiency and relative heat loss.

Overall, the methods rank Kolding Nord as the most inefficient DH network and Hover as the most efficient. It can be seen using TEF that some of the DH networks experience significant change while others keep their rank, e.g. Ullerup is adjusted up by 5 ranks. Contrary to Ullerup, e.g. Hvidsminde is adjusted down by 3 ranks, which is a result of suboptimal conditions in the DH network. 
Table 4. Overall ranking of the DH network areas based on efficiency, relative distribution heat loss and TEF

\begin{tabular}{|c|c|c|c|c|c|c|}
\hline No & Area & $\boldsymbol{\eta}, \boldsymbol{\%}$ & $\boldsymbol{q}_{\boldsymbol{l}}, \boldsymbol{\%}$ & Area & TEF & $\Delta$ \\
\hline 1 & Hover & 91 & 53.84 & Hover & -50.5 & 0 \\
\hline 2 & Gludsm. & 88 & 15.25 & Gludsm. & -4.6 & 0 \\
\hline 3 & Nørrem. & 82 & 44.44 & Bredb. & 7.2 & 2 \\
\hline 4 & Snoghøj & 80 & 98.41 & Snoghøj & 10.8 & 0 \\
\hline 5 & Bredb. & 79 & 4.06 & Nørrem. & 35.3 & -2 \\
\hline 6 & Erritsø & 77 & 47.10 & $\begin{array}{c}\text { Kolding } \\
\text { M/S }\end{array}$ & 38.5 & 1 \\
\hline 7 & $\begin{array}{c}\text { Kolding } \\
\text { M/S }\end{array}$ & 77 & 222.00 & Ullerup & 41.1 & 5 \\
\hline 8 & Strand. & 74 & 338.81 & Strand. & 42.8 & 0 \\
\hline 9 & Taulov & 74 & 60.88 & Erritsø & 42.8 & -3 \\
\hline 10 & Hvidsm. & 71 & 30.09 & Taulov & 44.1 & -1 \\
\hline 11 & Skærb. & 71 & 80.62 & Skærb. & 52.4 & 0 \\
\hline 12 & Ullerup & 70 & 54.17 & Egeskov & 69.4 & 1 \\
\hline 13 & Egeskov & 70 & 43.28 & Hvidsm. & 118.7 & -3 \\
\hline 14 & $\begin{array}{c}\text { Kolding } \\
\text { Nord }\end{array}$ & 68 & 31.90 & $\begin{array}{c}\text { Kolding } \\
\text { Nord }\end{array}$ & 162.0 & 0 \\
\hline
\end{tabular}

\section{Discussion}

Generally, this report is governed by a trial and error approach, as the subject of comparing independent $\mathrm{DH}$ networks based on balanced parameters is very lightly studied. Only very few relevant papers could be found on the subject after conducting an extensive literature review. This means that there are possibly untried approaches to dealing with the problem, which may change or support the current conclusions and results.

The above analysis shows that TEF values give an overall good understanding of how the different $\mathrm{DH}$ networks perform. It can, however, be hard to determine the decisive parameter in the TEF, i.e. find out whether the TEF a result of over-dimensioned pipes or high operating temperatures. Furthermore, as stated in Section 4 , the methodologies used to evaluate the DH networks give the same results for the best and worst-performing networks. This can be attributed to Kolding Nord and Hover being significantly better or worse, resulting in no overall change, in this case, when no change is present for the worst performing network. The overall need to use TEF as an economic tool is questionable as Trefor Varme is likely to focus on the network with the lowest performance. For the cases between Kolding Nord and Hover, TEF becomes useful, and for the cases where the DH networks may be closer in quality, the tool increases its economical relevance.

Kolding Nord is established as the DH network with the worst performance, see Table 4. Kolding Nord has a waste incineration plant that is given priority in production due to legislation. This can saturate the demand of Kolding Nord create the need to export the heat to Kolding M/S using a heat exchanger. The temperature is slightly higher to compensate for heat exchange losses, see Table 3. Recently the waste incineration plant was expanded with a cooling circuit to be used during the hours with excess production to accommodate potential damage to the DH network. This shows how disproportionality in DH network topology can result in significant heat losses.

\subsection{Future work}

Based on the work documented in this paper, some suggestions for further work within the field can be made. These suggestions can help in further understanding and economic benefit analysis of the $\mathrm{DH}$ renovation under the 4th generation district heating transformation. Among other things, this approach offers a suitable sensitivity method for studying the effect of a reduced temperature level in new or renovated networks.

In this paper, the DH networks were compared for the year 2017. Using the presented methodology, a series of years could be analyzed to follow an overall trend in TEF. For instance, Gludsminde has a very low TEF of -4.55 due to significant renovations in this area. Analyzing the trend in TEF before and after the renovation useful conclusions can be made on TEF development, which can be applied to other worst-performing networks. It should be noted that the data available aside from 2017 and 2015 was significantly flawed, and adjustment and interpolation of the data sets may be necessary.

Using the TEF documented in this report, companies can evaluate their DH network inventory on a network level. However, if the TEF calculations were used in connection with the company pipe records and renovation prices on the given pipe sections an algorithm could be developed to pinpoint the areas with the best ratio between cost and improvement in TEF.

In this report, the initial steps of multiparameter regression are made. Further work could be done into examining the weighting of the individual parameters constituting the multi-parameter to gain insight into the significance of the parameters when running optimization.

\section{Conclusion}

Based on the obtained results and the discussed parameters, fourteen DH networks were examined. The multivariate statistical method was proposed and applied to compare and rank the existing distribution systems in Denmark. The DH network efficiencies were found to be in the range of 68 - $92 \%$. The DH network diversity was established, and a set of parameters was compared based on efficiency. The chosen parameters were: operation temperature, pipe series, pipe age, number of twin pipes, energy density, and pipe lambda value. Relevant parameters were adjusted according to their respective impact on the overall DH network.

It was found that a single parameter cannot be used to compare the networks. Therefore, the most influential parameters were collected in a multiparameter, giving an overall coefficient of determination of $\mathrm{R}^{2}=0.7265$. Collectively, it was determined that Kolding Nord is the 
DH network with the lowest performance and Hover is the DH network with the highest performance. The comparison was made using efficiency, relative heat loss, and a technical evaluation factor. The technical evaluation factor was found in literature and evaluated using traditional series 1 steel pipes and Conti series 3 steel pipes.

The technical evaluation factor can be used as a tool to determine $\mathrm{DH}$ networks with the highest renovation potential and can hence be used as a tool for economic benefit analysis. The efficiency and relative heat loss showed an identical ranking of the $\mathrm{DH}$ networks, whereas the technical evaluation factor ranking turns out to be different. The methods were compared to establish the change in ranking associated with the use of the three methods. Ullerup experienced the largest change being adjusted up by 5 ranks using the technical evaluation factor, Hvidsminde and Errits $\varnothing$ were both adjusted down by 3 ranks.

Considered case studies show further the direction for developing the statistical analysis of existing and future network performance and will be beneficial in studying of the 4th generation district heating grids. Future work in this direction will involve developing an algorithm for comparison of an array of district heating networks creating decision support for the best-practice renovation of pipe sections within target areas.

\section{Acknowledgements}

This paper could not have been made possible without the qualified guidance by the team at Trefor Varme. The work was supported by the Danish Ministry of Energy, Utilities, and Climate for the project DK Energy Live Lab - Vejle Nord (No. 2017-3451).

\section{References}

1. Dansk Fjernvarme. (2019). Fakta om fjernvarme. URL: https://www.danskfjernvarme.dk/presse/faktaomfjernvarme. Online; accessed 15 April 2019.

2. Fjernvarme Fyn. (2019). Fjernvarmens historie. URL: https://www.fjernvarmefyn.dk/videnomfjernvarme/historie/. Online; accessed 15 April 2019.

3. P. Woods, and J. Overgaard, (2016). Historical development of district heating and characteristics of a modern district heating system. In Advanced District Heating and Cooling (DHC) Systems, R. Wiltshire, Ed. Woodhead Publishing Series in Energy. Elsevier, number 87, p. 3. DOI= https://doi.org/10.1016/b978-1-78242-374-4.00001-x.

4. K. Sipilä, 2016. Cogeneration, biomass, waste to energy and industrial waste heat for district heating. In Advanced District Heating and Cooling (DHC) Systems, R. Wiltshire, Ed. Elsevier: Woodhead Publishing Series in Energy, number 87, p. 45. DOI= https://doi.org/10.1016/j.energy.2017.04.045.

5. O. Gudmundsson, J. E. Thorsen, M. Brand, (2018). The role of district heating in coupling of the future renewable energy sectors. Energy Procedia, 149 (Sep. 2018), $445 \quad$ - 454. DOI= https://doi.org/10.1016/j.egypro.2018.08.209.

6. EnergyLab Nordhavn. (2019). Annual Reports. URL: http://www.energylabnordhavn.com/annualreports.html. Online; accessed 15 October 2019.

7. M. Arnesano, J. Dyson, M. Fagiani, A. Mancini, G. M. Revel, M. Severini, S. Squartini, L. Zampetti, and P. Zingaretti, (2018). An IoT Solution for Energy Management at Building and District Level. 14th IEEE/ASME International Conference on Mechatronic and Embedded Systems and Applications (MESA). DOI= https://doi.org/10.1109/mesa.2018.8449168.

8. H. Lund, S. Werner, R. Wiltshire, S. Svendsen, J. E. Thorsen, F. Hvelplund, and B. V. Mathiesen, (2014). 4th Generation District Heating (4GDH): Integrating smart thermal grids into future sustainable energy systems. Energy. 68 (Apr. 2014), 1-11. DOI= https://doi.org/10.1016/j.energy.2014.02.089.

9. H. Lund, P. A. Østergaard, M. Chang, S. Werner, S. Svendsen, P. Sorknæs, J. E. Thorsen, F. Hvelplund, B. O. Gram Mortensen, B. V. Mathiesen, C. Bojesen, N. Duic, X. Zhang, , and B. Möller, (2018). The Status of 4th Generation District Heating: Research and Results. Energy. 164 (Dec. 2018), 147-154. DOI= https://doi.org/10.1016/j.energy.2018.08.206.

10. D. Rutz, C. Winterscheid, T. Pauschinger, S. Grimm, T. Roth, B. Doračić, G. Dyer, T. A. Østergaard, and R. Hummelsh $\varnothing \mathrm{j},(2019)$. Upgrading the performance of district heating networks. Technical and nontechnical approaches. A Handbook. WIP Renewable Energies, Munich, Germany, $1^{\text {st }}$ ed. URL: https://www.upgrade-

dh.eu/images/Publications\%20and\%20Reports/D2.5 2019-07-02_Upgrade-DH_Handbook_EN.pdf. Online; accessed 15 October 2019.

11. H. E. Hansen, P. Kjerulf-Jensen, , and O. B. Stampe, (2006). Varme- og Klimateknik, Grundbog, volume 1. Danvak ApS. $3^{\text {rd }}$ ed.

12. A. B. Lauritsen, (2009). Varme Ståbi, volume 1, Nyt Teknisk Forlag, $5^{\text {th }}$ ed.

13. S. Werner, and S. Frederiksen, 2013. District Heating and Cooling. Studentlitteratur AB.

14. A. J. Ghajar, Y. A. Cengel, (2014). Heat and Mass Transfer (in SI Units). McGraw-Hill Education (Asia).

15. E. Latosov, A.Volkova, A. Hlebnikov, and A. Siirde, (2018). Technical improvement potential of large district heating network: application to the case of Tallinn, Estonia. Energy Procedia, 149 (Sep. 2018), 337 - $344 . \quad$ DOI= https://doi.org/10.1016/j.egypro.2018.08.197.

16. Dansk Teknologisk Institut. (2019). Graddage. URL: https://rvv.dk/fjernvarme/graddage/. Online; accessed 12 February 2019. 
17. CEN/TC 107. (2010). Design og installation af præisolerede fastrørsystemer til fjernvarme. Dansk Standard. ds/en 13941 + a1:2010 edition.

18. V. Masatin, E. Latosef, and A.A. Volkova, and A. Siirde (2018). Evaluation factor for district heating network heat loss with respect to network geometry.
Energy Procedia, 95 (Sep. 2016), 279 - 285. DOI= https://doi.org/10.1016/j.egypro.2016.09.069.

19. Logstor. 2019. Logstor calculator. URL: http://calc.logstor.com. Online; accessed 15 October 2019. 